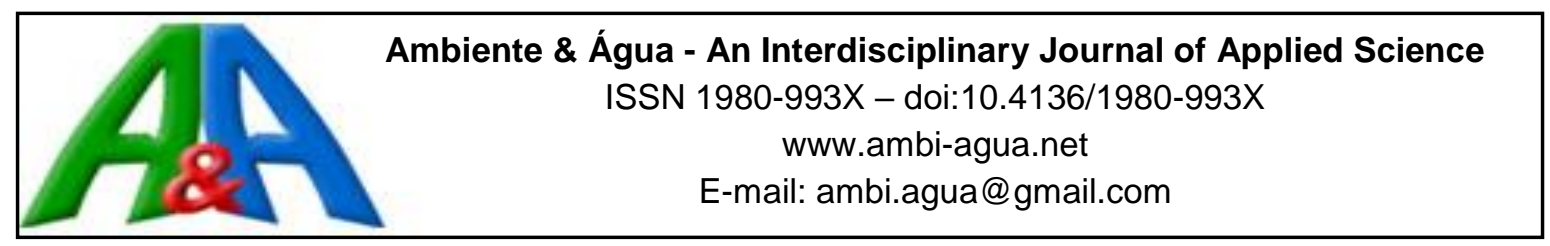

\title{
Índice de qualidade das águas e balneabilidade no Riacho da Bica, Portalegre, RN, Brasil
}

\author{
doi:10.4136/ambi-agua.1833
}

Received: 06 Jan. 2016; Accepted: 25 Apr. 2016

\author{
Samylle Ruana Marinho de Medeiros ${ }^{1^{*}}$; Rodrigo Guimarães de Carvalho ${ }^{1}$; \\ Luiz di Souza ${ }^{2}$; Antônio Helton da Silva Barbosa ${ }^{3}$

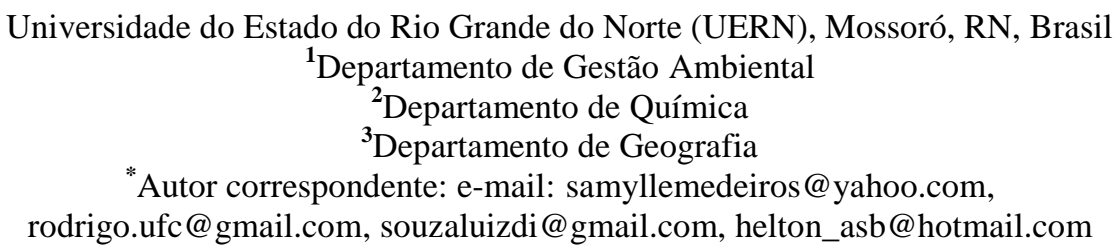

\section{RESUMO}

A qualidade das águas é caracterizada por parâmetros físicos, químicos e microbiológicos, os quais são submetidos constantemente a interferências de ordem natural, do próprio ecossistema, e de ordem antrópica, advindas das atividades de uso e ocupação do solo. No Estado do Rio Grande do Norte, Brasil, a melhoria da qualidade das águas exige atenção, tendo em vista que a região perde parte significativa de suas águas pelas altas taxas de evaporação. A cidade de Portalegre apresenta um conjunto paisagístico formado por nascentes perenes, brejos de altitude e cachoeiras. Considerando as características do local, este trabalho caracterizou a qualidade hídrica do Riacho da Bica que percorre a área de microbacia que se encontra na vertente norte do município e é bastante procurado para fins de recreação de contato primário. O objetivo da pesquisa foi a análise do Índice de Qualidade das Águas (IQA) em três pontos do Riacho da Bica e a análise da balneabilidade na Cachoeira do Pinga, frequentemente usada por banhistas. Os resultados mostram que a qualidade das águas é melhor na nascente do Riacho da Bica em que o IQA foi classificado como "regular". Os demais pontos do riacho foram classificados como "ruim". A balneabilidade das águas da Cachoeira do Pinga foi classificada como excelente.

Palavras-chave: análise microbiológica, parâmetros físicos e químicos, recursos hídricos.

\section{Water Quality Index and suitability for bathing of Bica Stream, Portalegre, RN, Brazil}

\begin{abstract}
Water quality is characterized by physical, chemical and microbiological parameters, which are constantly subject to the interference of nature, the ecosystem and human land-use activities. In Rio Grande do Norte State, Brazil, the improvement of water quality requires attention, considering that the region loses a significant portion of its waters through high evaporation rates. In this context, the town of Portalegre has a complex landscape formed by perennial springs, upper swamps and waterfalls. Considering the uniqueness of the area, this
\end{abstract}


research characterized the water quality of Bica Stream, which flows through the watershed area located on the north side of the city, and is very popular for leisure activities. This research analyzed the Water Quality Index (WQI) at three points of the Bica Stream, as well as the Pinga Waterfall's suitability for bathing, as it is frequently used for this purpose. The results show that the water quality is better at the spring of Bica Stream, with a WQI classified as "regular". The other parts of the stream were classified as "bad". The waterfall water was classified as excellent for bathing.

Keywords: microbiological analysis, physical and chemical parameters, water resources.

\section{INTRODUÇÃO}

Conhecer a qualidade das águas de um dado corpo hídrico para adequá-las aos seus mais variados usos, seja estes consuntivos ou não consuntivos, é uma tarefa importante. No semiárido brasileiro esta proposta é ainda mais imprescindível, uma vez que a disponibilidade hídrica, em termos quantitativos, é limitada pelo processo natural no qual as taxas de evaporação das águas superam a taxa de precipitação. Tal condicionante torna relevante a atuação de pesquisadores e gestores públicos na promoção da qualidade das águas (Silva et al., 2012).

No estado do Rio Grande do Norte, Brasil, o uso das águas para recreação de contato primário, associado ao desenvolvimento da atividade turística, é bastante significativo. Por se tratar de uma região de clima semiárido com o período de chuvas limitado e insolação na maior parte do ano, a procura por atrativos turísticos que proporcione este tipo de lazer acontece tanto no litoral como no interior.

Nos municípios interioranos, como é o caso de Portalegre, a população frequenta lugares próximos a rios, cachoeiras e até mesmo barragens para usufruir da recreação de contato primário. Como nesta atividade há possibilidade de aquisição de doenças transmitidas por contato com a água ou sua ingestão, a análise da balneabilidade é um instrumento indispensável para fornecer segurança ao banhista e, sobretudo, uma resposta quanto à qualidade sanitária da água (Francener et al., 2011).

O monitoramento da balneabilidade a nível institucional tem se dado através do Programa Água Azul, o qual é realizado pelo Instituto do Desenvolvimento Sustentável e Meio Ambiente (IDEMA) e pelo Instituto de Gestão das Águas do Estado (IGARN) em parcerias com as instituições de ensino federais (UFRN, UFERSA e IFRN) e estaduais (UERN e EMPARN) e tem se dedicado a analisar a balneabilidade apenas das praias do estado (IDEMA, 2008).

Sendo assim, surge a preocupação quanto à balneabilidade das águas doces no estado do Rio Grande do Norte, Brasil, preocupação que também já foi evidenciada em outros estados brasileiros. Conforme destacaram Lopes e Magalhães Junior (2010, p. 134) ao avaliarem a Bacia do Alto Rio das Velhas em Minas Gerais, observaram que há uma carência de estudos e programas de monitoramento que avaliem as condições de balneabilidade, especialmente em balneários de águas doces.

Os corpos hídricos poluídos e/ou contaminados por águas residuárias oferecem um risco potencial de expor os banhistas a doenças de veiculação hídrica, principalmente as gastrenterites. Neste sentido, a balneabilidade atua com o objetivo de refletir a qualidade das águas de recreação, sendo de suma importância a sua avaliação como uma política de saneamento (Francener et al., 2011). O Riacho da Bica, localizado no município de Portalegre, conta com uma área de Cachoeira, conhecida como Cachoeira do Pinga, cuja declividade é de $70^{\circ}$. O lugar é bastante visitado para fins de lazer, balneabilidade e contemplação paisagística.

No entanto, é importante destacar que Portalegre é uma cidade com ocupação urbana em consolidação desprovida de alguns serviços básicos de saneamento e de uma política de 
gestão de resíduos sólidos. Segundo o IBGE (2014), o município não se encontra entre as cidades com serviços de esgotamento sanitário. Tal situação favorece para que os dejetos das residências sejam dispostos sobre o solo ou acondicionados em estruturas rudimentares, como valas e fossas artesanais, contribuindo assim, com a incidência de efluentes não tratados nos corpos hídricos e com o aumento dos níveis de contaminação por bactérias termotolerantes na Cachoeira do Pinga.

Tendo em vista esta problemática, a caracterização e a avaliação da qualidade da água do Riacho da Bica são fundamentais para conhecimento público e mobilização para criação de políticas de uso e conservação. Todavia, para que essas informações cheguem aos usuários deste recurso os métodos de avaliação da qualidade das águas devem ser de compreensão fácil (Ferreira et al., 2015).

Neste sentido, destaca-se o relevante papel que os índices vêm desempenhando nessa área. Desenvolvidos para unificar, interpretar e divulgar os dados obtidos no monitoramento ambiental, os índices têm sido usados com êxito para caracterizar o estado e as tendências da qualidade da água. Os mesmos não exigem grande número de parâmetros de qualidade da água para o desenvolvimento, e a validação é necessária apenas para a concentração de um número limitado de parâmetros (Andrietti et al., 2016).

O Índice de Qualidade das Águas (IQA) é uma ferramenta capaz de traduzir os parâmetros de qualidade de um dado corpo hídrico reunindo-os em um único índice, usado para classificar sua qualidade, que pode variar de boa a ruim. Tal ferramenta contribui, sobretudo, no diálogo com o público não técnico, pois facilita a compreensão dos resultados obtidos com as análises físico-químicas (Freitas et al., 2011), sem a necessidade de seu conhecimento técnico.

Tendo em vista o papel do IQA e da balneabilidade na elucidação da qualidade ambiental de um corpo hídrico, o presente trabalho visa contribuir com informações acerca do Riacho da Bica, um curso d'agua que percorre a microbacia da Mata da Bica, a qual está localizada adjacente à área urbana, na vertente norte do município de Portalegre. O curso d’àgua supracitado é bastante utilizado para fins de recreação de contato primário e abastecimento pela comunidade para fins domésticos. Desta forma, o objetivo central do trabalho consistiu na caracterização da qualidade hídrica do Riacho da Bica, a partir do IQA e da análise de sua balneabilidade.

\section{MATERIAL E MÉTODOS}

\subsection{Caracterização da Área de Estudo}

O município de Portalegre está situado na mesorregião do Oeste Potiguar, sobre um maciço cristalino, numa altitude média de $642 \mathrm{~m}$ e coordenadas $06^{\circ} 01^{\prime} 26,4^{\prime \prime}$ de latitude sul e $37^{\circ} 59^{\prime} 16,8^{\prime \prime}$ de longitude oeste (IDEMA, 2008). O município possui uma área territorial de $110,054 \mathrm{~km}^{2}$ (IBGE, 2014) e estabelece limites com os municípios de Riacho da Cruz, Taboleiro Grande, Viçosa, Serrinha dos Pintos, Francisco Dantas e Martins.

Situado na região serrana do Oeste do estado do Rio Grande do Norte, Brasil, e no médio curso da Bacia Hidrográfica do Rio Apodi Mossoró, Portalegre apresenta um conjunto paisagístico com características de excepcionalidade climática devido à influência do relevo na circulação atmosférica, o que propicia maior precipitação, sendo comuns os anos com chuvas acima dos $1.400 \mathrm{~mm}$. Soma-se a esse fenômeno o fato de existir um capeamento sedimentar no topo da serra, entre $630 \mathrm{~m}$ e $700 \mathrm{~m}$, que absorve as águas pluviais e as redistribui, especialmente, na vertente norte/nordeste, formando setores brejados no terço superior das vertentes, com nascentes perenes e uma mata subcaducifólia no seu entorno (Medeiros, 2015).

O mais conhecido brejo de altitude do município de Portalegre está localizado em uma 
vertente adjacente a área urbana. Neste ambiente, conhecido por Mata da Bica (MB) (Figura 1), foi criado o Terminal Turístico da Bica (TTB), uma área com uma infraestrutura básica de restaurante, banheiros, bancos e fontes de água voltadas para atender o visitante.

A partir da nascente que está situada no TTB seguindo o curso da vertente norte, em uma altitude de aproximadamente $500 \mathrm{~m}$, ocorre ainda uma cachoeira denominada Cachoeira do Pinga. Como não há instituído um nome oficial para este curso d'água que perpassa a microbacia da MB e contribui com a recarga da Cachoeira do Pinga optou-se por nomeá-lo de Riacho da Bica o qual foi objeto de análise deste estudo.

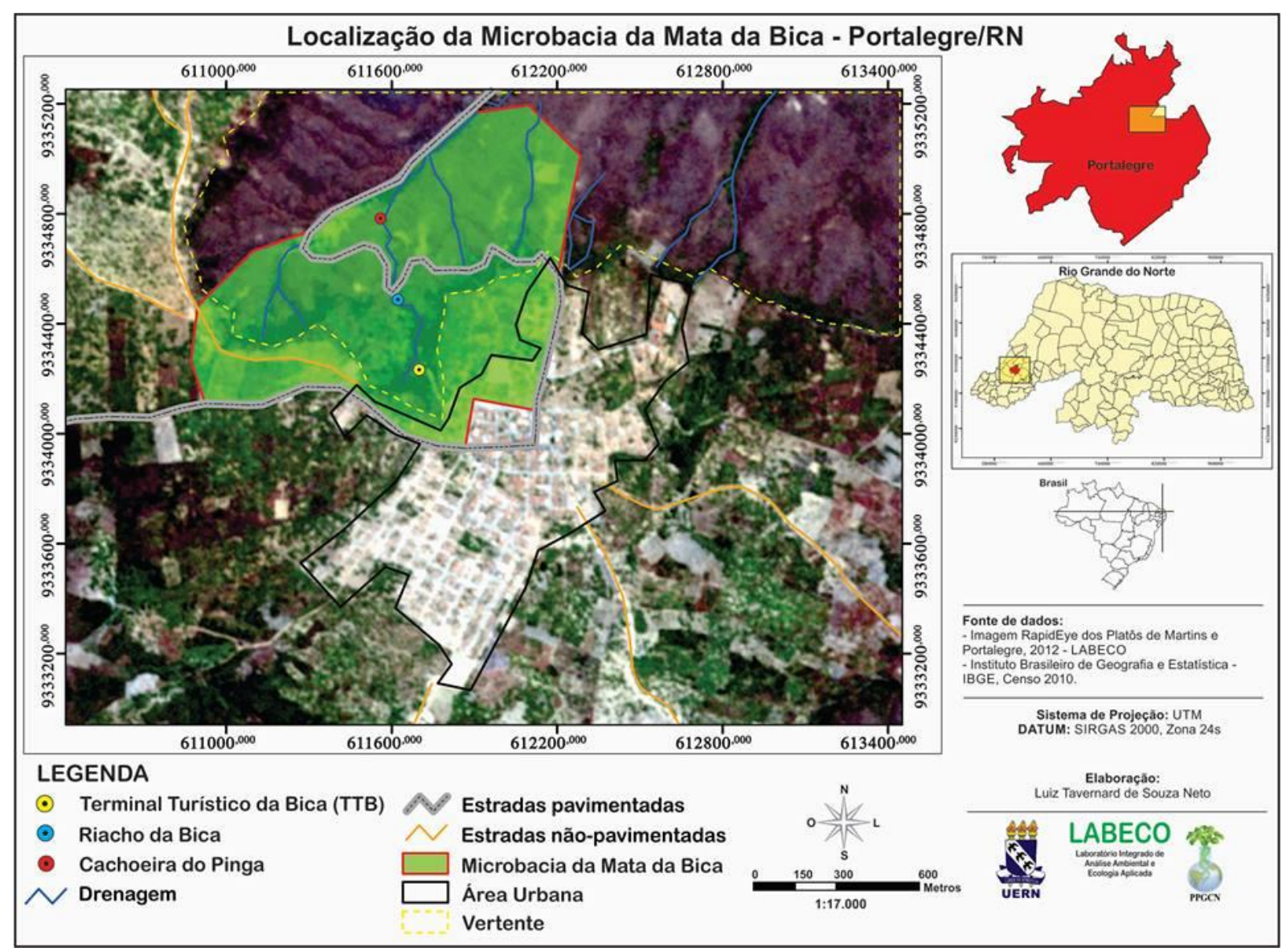

Figura 1. Localização da área de estudo.

\subsection{Procedimentos Experimentais para análise do IQA}

Para a análise do IQA, as águas foram coletadas nos três pontos específicos do Riacho da Bica. Conforme destacado na Figura 1, o primeiro ponto (P1), amarelo, corresponde à fonte de água do TTB, localizada a $620 \mathrm{~m}$ de altitude. O segundo ponto (P2), cor azul, foi no trecho de água corrente, localizado à jusante do primeiro ponto, a $570 \mathrm{~m}$ de altitude. $\mathrm{O}$ terceiro ponto (P3) de coleta, de cor vermelha, foi na própria Cachoeira do Pinga, local onde as águas são usadas para banho. Este ponto localiza-se a $485 \mathrm{~m}$ de altitude.

Estes três pontos foram fundamentais para a observância dos padrões de qualidade, se estes estão sendo violados ou não. No entanto, apenas na Cachoeira do Pinga foi analisada a balneabilidade.

Tendo em vista que a variação climática interfere nos parâmetros analisados, as amostras para análise do Índice de Qualidade Ambiental (IQA) foram coletadas em duas campanhas, uma no mês de julho (09/07/2014), e outra no mês de novembro (26/11/2014), períodos referentes, respectivamente, ao período chuvoso e de estiagem. Para tanto, formulou-se a 
ficha de coleta e uma tabela com as observações a serem seguidas de acordo com cada parâmetro que seria analisado (Tabela 1).

Tabela 1. Parâmetros, coletores, condições de preservação e tempos de armazenamentos usados para coleta e análise das amostras.

\begin{tabular}{|c|c|c|c|}
\hline Indicador & Recipiente & Preservação & $\begin{array}{c}\text { Tempo de } \\
\text { Armazenamento }\end{array}$ \\
\hline $\begin{array}{l}\text { Oxigênio dissolvido, } \\
\text { pH e temperatura }\end{array}$ & Medido in situ & Medido in situ & Medido in situ \\
\hline $\begin{array}{l}\text { Coliformes } \\
\text { Termotolerantes }\end{array}$ & $\begin{array}{l}\text { Vidro, plástico } \\
\text { esterilizado à } \\
105^{\circ} \mathrm{C} ; 1 \mathrm{~atm},\end{array}$ & Refrigerar a $4^{\circ} \mathrm{C}$ & 24 horas \\
\hline DBO & Vidro, plástico & Refrigerar a $4^{\circ} \mathrm{C}$ & 6 horas \\
\hline Nitrogênio total & Vidro, plástico & $\begin{array}{l}\mathrm{H} 2 \mathrm{SO} 4 \text { conc. até } \mathrm{pH} \\
<2 . \text { Refrigerar a } 4^{\circ} \mathrm{C}\end{array}$ & 28 dias \\
\hline Turbidez & Vidro, plástico & $\begin{array}{l}\text { Refrigerar } 4^{\circ} \mathrm{C} \text { e manter ao } \\
\text { abrigo da luz }\end{array}$ & 24 horas \\
\hline Sólidos totais & Vidro, plástico & Refrigerar $4^{\circ} \mathrm{C}$ & 7 dias \\
\hline Fósforo Total & Vidro & $\begin{array}{l}\mathrm{H} 2 \mathrm{SO} 4 \text { conc. até } \mathrm{pH} \\
<2 \text { e Refrigeração } 4^{\circ} \mathrm{C}\end{array}$ & 28 dias \\
\hline
\end{tabular}

Fonte: Silva e Souza (2013) (adaptado).

As amostras foram coletadas de acordo com as normas prescritas na literatura (Brasil, 2006; ABNT, 1987). O IQA é utilizado pela Companhia Ambiental do Estado de São Paulo - CETESB desde 1975, e nas décadas seguintes os demais estados brasileiros passaram a adotá-lo, sendo atualmente o principal índice de qualidade da água utilizado no país (ANA, 2015).

O mesmo é obtido através das análises de nove parâmetros, em que para cada parâmetro é estipulado um peso (valor), que será refletido no cálculo final. São analisados no IQA o Oxigênio Dissolvido (OD) (Peso-0,17), os Coliformes Termotolerantes (CT) (Peso 0,15), o Potencial Hidrogênionico (pH) (Peso-0,12), a Demanda Bioquímica de Oxigênio (DBO 5,20) (Peso-0,10), os Sólidos Totais (ST) dissolvidos (Peso-0,08), o Fósforo Total (PT) (Peso-0,10), o Nitrogênio Total (NT) (Peso-0,10), a Temperatura $(0,10)$ e a Turbidez (Tur.) $(0,08)$ (CETESB, 2015).

No presente trabalho o IQA foi calculado a partir de uma plataforma online do site da CETESB (http://portalpnqa.ana.gov.br/indicadores-indice-aguas.aspx). na qual o índice é obtido de uma maneira mais rápida que o cálculo manual, e se dá a partir do preenchimento de uma base online que solicita os valores para cada parâmetro, apresentando posteriormente o valor do IQA. A única observação que deve se tomar cuidado, é que o OD solicitado pela plataforma é o OD saturado (\%), necessitando que o interessado no IQA faça a transformação dos valores antes de preencher.

Quanto aos procedimentos de análise, as medidas de $\mathrm{OD}, \mathrm{pH}$ e a temperatura foram medidos em campo utilizando-se um medidor multiparamétrico portátil Orion 5-Star da Thermo Scientific, os demais parâmetros (CT. DBO, NT, Tur. PT e ST) foram quantificados em laboratório utilizando-se das estruturas dos laboratórios de Biologia I, de Eletroquímica e Química Analítica (LEQA) e do Laboratório de Catálise, Ambiente e Materiais (LACAM), todos pertencentes a Universidade do Estado do Rio Grande do Norte (UERN). As determinações de todas estas variáveis foram feitas usando métodos padrões do Standard Methods of APHA (APHA et al., 2005), e as medidas foram feitas em triplicata, 
considerando-se a média aritmética como o resultado. Em casos em que um dos resultados ficou muito afastado da média, este foi descartado e foi considerado como resultado a média dos dois resultados que apresentaram valores próximos ou semelhantes.

As análises de Tur. e PT foram realizadas via espectroscopia molecular, utilizando-se um Espectrofotômetro UV-Visível (Figura 2), modelo UV-mini, marca SHIMADZU. Em todos os casos as amostras foram lidas, após preparo adequado seguindo metodologia padrão, em uma curva padrão pré-montada com soluções padrões no comprimento de onda característico de maior magnitude de absorção de cada composto e o resultado sendo fornecido pelo aparelho em $\mathrm{mg} \mathrm{L}^{-1}$, após comparação do valor da leitura com sua posição na curva padrão arquivada.

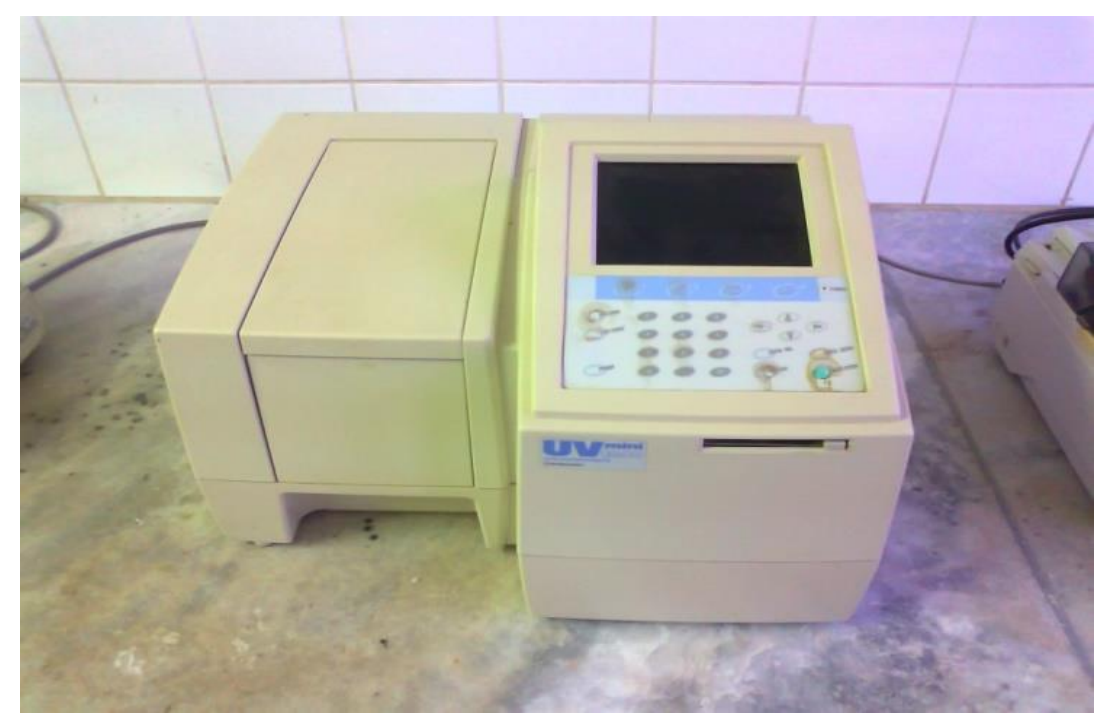

Figura 2. Espectrofotômetro UV-Visível modelo UV-mini 1240 da marca SHIMADZU.

As análises de ST foram feitas gravimetricamente usando cadinhos de porcelana e uma estufa comum. Os cadinhos foram lavados e secos na estufa, logo após, os mesmos são resfriados no dessecador para a posterior pesagem e determinação de sua massa. Foi utilizado $25 \mathrm{~mL}$ de amostra, que foi adicionada em cada cadinho. Concluindo este procedimento, os cadinhos são colocados na estufa a uma temperatura de $105^{\circ} \mathrm{C}$ até a completa evaporação do líquido (aproximadamente 8 horas). Após as 8 horas, retiram-se os cadinhos e os coloca novamente no dessecador para alcançarem a temperatura ambiente para serem pesados com 0 resíduo. O ST foi então calculado pela Equação 1.

$$
S T\left(m g L^{-1}\right)=(M a-M v) \times 4 \times 10^{4}
$$

em que:

Ma é a massa do cadinho com a amostra (g); e

Mv é a massa do cadinho vazio $(\mathrm{g})$.

No que diz respeito aos teores de nitrogênio total - NT, estes foram determinados segundo o método de Kjeldahl proposto por (Miyazawa et al., 1999). Este método é dividido essencialmente em três etapas de análise distintas: digestão, destilação e titulação. No processo de digestão, a matéria orgânica presente na amostra é decomposta, sob aquecimento, utilizando-se ácido sulfúrico concentrado e uma mistura de catalisadores (sulfato de cobre + sulfato de sódio). Neste processo, todo o nitrogênio presente na amostra é transformado em um sal de amônio. 
Em seguida, no processo de destilação, o íon amônio presente no sal formado reagiu com o íon hidróxido que, sob aquecimento, liberou amônia que, por sua vez, é inserida na solução saturada de ácido bórico.

A próxima etapa consistiu na titulação, em que o íon borato que foi deslocado da reação da amônia com ácido bórico foi titulado com uma solução padrão de ácido clorídrico. A quantidade de nitrogênio presente na amostra é determinada através do volume medido de ácido clorídrico padrão gasto na titulação. Os procedimentos detalhados referentes a essas etapas estão descritos a seguir:

\section{Digestão com $\mathrm{H}_{2} \mathrm{SO}_{4}+\mathrm{H}_{2} \mathrm{O}_{2}$}

a) Transferiu-se aproximadamente $0,5 \mathrm{~g}$ de material para um tubo digestor e adicionou-se $1 \mathrm{~g}$ da mistura de sais de sulfato de sódio com sulfato de cobre (10:1), $3 \mathrm{~mL}$ de $\mathrm{H}_{2} \mathrm{SO}_{4} 98 \%$ e $1 \mathrm{~mL}$ de $\mathrm{H}_{2} \mathrm{O}_{2} 30 \%$;

b) Colocou-se o tubo no bloco digestor, aqueceu-se lentamente até $350^{\circ} \mathrm{C}$ e manteve-se até a obtenção de um líquido viscoso, azulado.

\section{Destilação e titulação}

a) Conectou-se o tubo digestor no destilador de nitrogênio;

b) Conectou-se na extremidade do destilador um erlenmeyer de $250 \mathrm{~mL}$ contendo $25 \mathrm{~mL}$ de $\mathrm{H}_{3} \mathrm{BO}_{3} 2 \%$ e 3 gotas da mistura de indicador azul de metileno $0,2 \%$ e vermelho de metila $0,2 \%$. Após a conexão do erlenmeyer adicionou-se $10 \mathrm{~mL}$ de $\mathrm{NaOH} 40 \%$ ao tubo do digestor;

c) Abriu-se a torneira do vapor de água para aquecimento e destilou-se até obter-se cerca de $45 \mathrm{~mL}$ no erlenmeyer. A coloração da solução de ácido bórico passa de azul para verde;

d) Titulou-se com solução padrão de $\mathrm{HCl} 0,1 \mathrm{~mol} \mathrm{~L}^{-1}$. No ponto final da titulação a coloração inicial azul é recuperada;

e) Anotou-se o volume gasto de $\mathrm{HCl}$ na titulação;

f) Calculou-se a concentração de nitrogênio total em g/100g utilizando a seguinte Equação 2.

$N$ total $(g / 100 g)=[(V \times C \times M M) \times 100] \div M$

em que:

$\mathrm{N}$ total $(\mathrm{g} / 100 \mathrm{~g})$ é a concentração de nitrogênio total em g/100g;

$\mathrm{V}$ é o volume gasto de $\mathrm{HCl}$ na titulação em litros;

C é a concentração do $\mathrm{HCl}$ em mol L ${ }^{-1}$;

MM é a massa molar do nitrogênio em $\mathrm{g} / \mathrm{mol}$; e

M é a massa utilizada da amostra em gramas.

Quanto às análises de DBO, cabe destacar que as amostras foram preparadas em garrafas específicas, e posteriormente foram encaminhadas para incubação por 5 dias à $20^{\circ} \mathrm{C}$ na ausência de luz. O ensaio para determinação da DBO foi realizado no Laboratório de Eletroquímica e Química Analítica (LEQA) da Universidade do Estado do Rio Grande do Norte (UERN), os procedimentos utilizados foram baseados na metodologia 5210 B do Standard Methods (APHA et al., 2005).

De acordo com esta metodologia, duas amostras foram preparadas para cada ponto (adição de $20 \mathrm{ml}$ de amostra em cada frasco). Em uma primeira amostra (DBO inicial) foi adicionado $\mathrm{KI}$ e $\mathrm{MnSO}_{4} \cdot \mathrm{H}_{2} \mathrm{O}$ (fixadores de oxigênio), ácido sulfúrico, amido (indicador) e 
em seguida titula-se contra uma solução tiossulfato padronizado. Na outra amostra $\left(\mathrm{DBO}_{5}\right)$ foi adicionada água de diluição e encubada durante cinco dias a uma temperatura constante de $20^{\circ} \mathrm{C}$. Encerrado o tempo de incubação, repetiu-se o processo de titulação que foi utilizado para determinação da DBO inicial. Por fim, o resultado da DBO 5,20 para cada ponto foi definido pela diferença entre a DBO final e $\mathrm{DBO}_{5}$ (Silva, 2013).

No que se refere aos valores de Coliformes termotolerantes cabe ressaltar que estes foram estipulados a partir dos valores de Escherichia coli (E. coli) (Hachich et al., 2012). Os mesmos foram calculados a partir de análises microbiológicas feitas pelo laboratório de biologia da UERN, utilizando o método Colitag, um teste rápido que identifica em 24 horas a presença de Coliformes totais e E. coli. Este método é aprovado pela United States Environmental Protection Agency (USEPA) e promove a reativação e posterior detecção de E. coli. No campo de pesquisa, o uso de métodos rápidos se torna vantajoso por diminuírem o tempo de análise e aumentarem a produtividade laboratorial (Marquezi et al., 2010).

Em virtude deste método não identificar Coliformes termotolerantes, que é o parâmetro microbiológico do IQA, chegou-se a uma estimativa dos valores de Coliformes termotolerantes a partir da relação de proporcionalidade entre os valores de E. coli e de Coliformes termotolerantes. Tal fundamento se baseou em alguns trabalhos renomados da área como o estudo de Hachich et al. (2012), o qual comparou as densidades de Coliformes termotolerantes e E. coli em 25 locais de água doce no estado de São Paulo e verificou que existia uma proporção de 84,3\% em média, concluindo que para 1.000 Coliformes Termotolerantes 800 corresponderia a E. coli (Hachich et al., 2012).

No estudo realizado por Sato et al. (2008) foi verificado que a E. coli corresponde a $63 \%$ do valor de coliformes termotolerantes. Outras pesquisas desenvolvidas em diferentes condições encontraram proporções variáveis entre $84 \%$ e $104 \%$, para as concentrações desses microrganismos (Sato et al., 2008).

Diante disso, considerando que a $E$. coli é a bactéria predominante do grupo dos coliformes termotolerantes, optou-se neste trabalho adotar a proporção de $84 \%$, ou seja, para um valor de $200 \mathrm{NMP} / 100 \mathrm{ml}$ de Coliformes termotolerantes, $168 \mathrm{NMP} / 100 \mathrm{ml}$ corresponderia ao valor de E. coli. A escolha do percentual de $84 \%$ se justifica em virtude de ser este o valor referente à média das três proporções encontradas em outros estudos $(63 \%$, $84 \%$ e $104 \%$ ), a média foi feita para não tornar a escolha tendenciosa.

Após a obtenção dos valores do IQA, foi feita a classificação do Riacho da Bica. Segundo a Agência Nacional das Águas - ANA, o valor final do IQA é classificado em faixas, que variam entre os estados brasileiros (ANA, 2015). Para o estado do Rio Grande do Norte, Brasil, são estabelecidas as seguintes faixas da avaliação atribuída:

$$
\begin{array}{ll}
91-100 & \text { - a água é ótima; } \\
71-90 & \text { - a água é boa; } \\
51-70 & \text { - a água é razoável; } \\
26-50 & \text { - a água é ruim; } \\
0-25 & \text { - a água é péssima. }
\end{array}
$$

\subsection{Procedimentos experimentais para análise da balneabilidade}

O trabalho de coleta de água para fins de análise da balneabilidade da Cachoeira do Pinga ocorreu tanto no período de influência da precipitação (mês de julho) quanto no período de estiagem da região (novembro/dezembro). Contudo, em virtude de falhas técnicas, os dados do período de precipitação foram comprometidos, não havendo tempo hábil para refazer as coletas e análises.

Em decorrência do imprevisto, a análise proferida neste trabalho corresponde apenas à 
campanha feita no período de estiagem. A coleta foi desenvolvida durante cinco semanas, abrangendo os meses novembro/dezembro de 2014, durante os dias 05/11, 12/11, 19/11, 26/11 e 03/12. Apesar da análise se restringir a esta última campanha, os dados obtidos não perdem seu valor, uma vez que é no período de estiagem que há uma maior procura de turistas para o lazer e balneabilidade na Cachoeira do Pinga, sendo, portanto, uma relevante fonte de informação para a população local e os visitantes da área.

O parâmetro microbiológico analisado nas amostras foi a E. coli. A definição da categoria de balneabilidade da Cachoeira foi aferida conforme a resolução 274/2000 do CONAMA, para a qual a categoria de balneabilidade varia de acordo com as proporções de E. coli em $100 \mathrm{ml}$.

A determinação do Número Mais Provável de E. coli foi realizada pelo método de fermentação em tubos múltiplos (FTM) a partir do reagente Colitag, para tanto foram utilizados os seguintes materiais: bico de Bunsen, lâmpada Ultra-Violeta, estufa incubadora a $35^{\circ} \mathrm{C}$ e tubos de ensaio, os procedimentos de análise seguiu o protocolo do "Standard Methods"(APHA et al., 2005).

\section{RESULTADOS E DISCUSSÃO}

\section{1. Índice de Qualidade das Águas (IQA) do Riacho da Bica}

Os resultados obtidos nas análises realizadas encontram-se dispostos na Tabela 2. A campanha 1 corresponde ao período de chuva na área de estudo e a campanha 2 refere-se ao período de estiagem. A partir da exposição destes dados, é possível fazer comparações prévias entre os três pontos e os períodos de coleta, contudo, as evidências mais relevantes estão discutidas nos próximos subtítulos do artigo.

Tabela 2. Propriedades físico-químicas e biológicas da água dos pontos amostrados.

\begin{tabular}{|c|c|c|c|c|c|c|}
\hline \multirow{2}{*}{ Parâmetros do IQA } & \multicolumn{2}{|c|}{ P1 } & \multicolumn{2}{|c|}{$\mathrm{P} 2$} & \multicolumn{2}{|c|}{ P3 } \\
\hline & Camp.1 & Camp.2 & Camp.1 & Camp.2 & Camp.1 & Camp.2 \\
\hline Oxigênio Dissolvido/mg L ${ }^{-1}$ & 6,95 & 8,33 & 10,92 & 9,54 & 11,47 & 10,55 \\
\hline Potencial Hidrogeniônico & 5,20 & 5,30 & 5,00 & 5,00 & 5,00 & 6,30 \\
\hline $\mathrm{DBO} / \mathrm{mg} \mathrm{L}^{-1}$ & 17,24 & 7,94 & 16,23 & 18,06 & 18,80 & 24,49 \\
\hline Temperatura $/{ }^{\circ} \mathrm{C}$ & 27 & 27 & 23 & 27 & 21 & 25 \\
\hline Nitrogênio Total/ mg L ${ }^{-1}$ & 0,87 & 3,69 & 1.63 & 3,38 & 1.81 & 4,75 \\
\hline Fósforo Total/ mg L ${ }^{-1}$ & 0,02 & 0,04 & 1,34 & 1,44 & 1,74 & 1,94 \\
\hline Turbidez uT & 18 & 2,40 & 24 & 9,73 & 36 & 6,65 \\
\hline Resíduo Total/ $\mathrm{mg} \mathrm{L}^{-1}$ & $253 \mathrm{mg} \mathrm{L}^{-1}$ & $364 \mathrm{mg} \mathrm{L}^{-1}$ & 320 & 1418 & 290 & 1392 \\
\hline $\begin{array}{l}\text { Col. Termotolerantes/ } \\
\text { NMP/100 ml }\end{array}$ & Negativo & Negativo & 94 & 36 & 167 & 95 \\
\hline
\end{tabular}

\subsubsection{Análise do IQA do Ponto 1 (P1)}

A fonte de água (P1) está inserida no TTB e é recarregada diretamente por uma nascente que fica bem próxima, ambas possuem estrutura de pedras cercando a fonte e à montante da nascente tem-se uma vegetação arbórea arbustiva preservada. No P1 existe ainda uma placa de advertência proibindo a entrada de pessoas, o que diminui previamente o impacto antrópico. No entanto, ao redor da estrutura as pessoas transitam livremente, sendo presenciado algumas vezes em campo o odor proveniente de urina ao redor da fonte, que poderia contaminar a água. 
Neste local o IQA se manteve de acordo com a classe Razoável, conforme dispõe a Agência Nacional de Águas (2015). Durante o período de chuva, o índice apresentou o valor de 55,8 , e no período de estiagem o valor foi de 58,2 , não apresentando variação significativa entre os períodos.

Quando comparado aos demais pontos, o P1 foi o que se apresentou visualmente menos poluído, fato confirmado pelo IQA, que apontou o P1 como o ponto menos contaminado do Riacho da Bica. No P1 os valores para coliformes termotolerantes não deram positivos, já para coliformes totais, apresentaram valores positivos, $40 \mathrm{NMP} / 100 \mathrm{ml}$ no período chuvoso e no período de estiagem o valor subiu, >1600 NMP/100 ml. Os parâmetros do Oxigênio Dissolvido - OD e da Turbidez se mantiveram dentro do padrão estabelecido pela Resolução 357 do CONAMA para águas doces de classe 2 (Brasil, 2005), a qual delimita para OD valores não inferiores a $5 \mathrm{mg} \mathrm{L}^{-1}$ e para turbidez valores de até 100 unidades nefelométricas.

No P1 os valores para OD foram de $6,95 \mathrm{mg} \mathrm{L}^{-1}$ (Período chuvoso) e $8,33 \mathrm{mg} \mathrm{L}^{-1}$ (Período de estiagem), estes resultados estabelecem estreita relação com os valores da DBO, que foi mais alto no período chuvoso, $17,24 \mathrm{mg} \mathrm{L}^{-1}$, e menor na estiagem, com 7,94, demonstrando que o aumento da matéria orgânica biodegradável implica na diminuição do oxigênio dissolvido na água, já que bactérias aeróbicas demandam oxigênio para degradar a matéria orgânica. Para Jordão et al. (2007), a mensuração das concentrações de oxigênio dissolvido possibilita avaliar as condições naturais da água e detectar impactos ambientais como eutrofização e poluição orgânica.

Já a turbidez é o parâmetro que está mais atrelado ao material em suspensão presente nos corpos d'água que dificulta a penetração do feixe de luz (Santi et al., 2012). Tendo em vista que durante as chuvas a concentração de sólidos em suspensão aumenta consideravelmente, o valor da turbidez foi de $18 \mathrm{uT}$, bem maior que a turbidez do período de estiagem, que foi de 2,40 .

O pH do P1 não se enquadrou nos limites da Resolução 357 do CONAMA (Brasil, 2005), apresentando valores de 5,2 na primeira campanha e 5,3 na segunda campanha, revelando o caráter acido da água do P1, mesmo no período de estiagem, contrariando a hipótese de que a acidez da água tenha como causa principal o efeito das chuvas.

Os valores de $\mathrm{pH}$ refletem o poder solvente da água e, dessa forma, indica possível reações químicas com rochas e solos. Morais (2010), ao estudar a microbacia do rio Cabeça, na bacia do rio Corumbataí em São Paulo, verificou em três pontos amostrados valores entre cinco e seis para o $\mathrm{pH}$ e concluiu que pode ser resultado de condições naturais representadas pelas feições geológicas e pedológicas da área de estudo que influenciam o pH da águas superficiais da região.

Tal situação pode ser retratada na microbacia da Mata da Bica. A declividade da área favorece movimentos de massa de solo para a água, além do mais, estudos comprovam que o capeamento sedimentar que está acima da rocha cristalina não é mais profundo que $50 \mathrm{~m}$, e a ocorrência da nascente se dá justamente no contato do capeamento sedimentar com o cristalino ficando a água exposta as reações químicas que ocorrem nessas três interfaces: solo, água e rocha.

Em suma, os valores do IQA do P1 são semelhantes aos valores encontrados por Manoel e Carvalho (2014), ao estudarem o IQA de duas nascentes no município de Ilha Solteira (SP), uma localizada no córrego das Lagoas e a outra no córrego do Ipê. A nascente do córrego das lagoas no período de estiagem manteve a água boa, e no período de chuva a água foi classificada como regular. Já a nascente do córrego do Ipê apresentou classificação boa nos dois períodos.

O IQA da nascente do córrego das lagoas durante o período de chuva coincidiu com os valores da fonte de água no TTB. Diferentemente do que foi observado por Manoel e Carvalho (2014), na MB não se obteve melhora na classificação da água durante o período de 
estiagem.

Todavia, mesmo com resultados satisfatórios, Manoel e Carvalho (2014) afirmaram que na região não há uma visão preservacionista dos recursos naturais. Para o TTB de Portalegre, existe o interesse na conservação da área, mas é preciso avançar bastante para se alcançar o olhar preservacionista das nascentes e fontes de água da área.

\subsubsection{Análise do IQA do Ponto 2 (P2)}

O segundo ponto (P2), correspondente ao trecho intermediário do Riacho da Bica, se encontra em uma altitude de $570 \mathrm{~m}$. Neste local foram identificados resíduos sólidos como fraldas descartáveis e garrafas pets, caracterizando uma poluição pontual. Este trecho do Riacho da Bica obteve uma classificação inferior ao P1, e se manteve dentro da classe Ruim nos dois períodos analisados. O P2 recebe influência, principalmente, dos efluentes do TTB, já que, por se tratar de uma área de declive as águas servidas do P1 chegam mais rapidamente neste trecho e se acumulam em alguns locais de água parada.

A Figura 3 apresenta o registro fotográfico feito do P2 durante o período de estiagem, demonstrando a degradação da qualidade da água através de uma espuma branca acumulada em uma porção de água entre as rochas do córrego do P2.

A situação reproduzida na Figura 3 é extremamente importante para entender a correlação com os valores obtidos para o resíduo total do P2 durante o período de seca. Isto porque os valores foram muito diferentes nos três pontos durante a campanha chuvosa e divergiram também dos valores do P1 no período de seca.

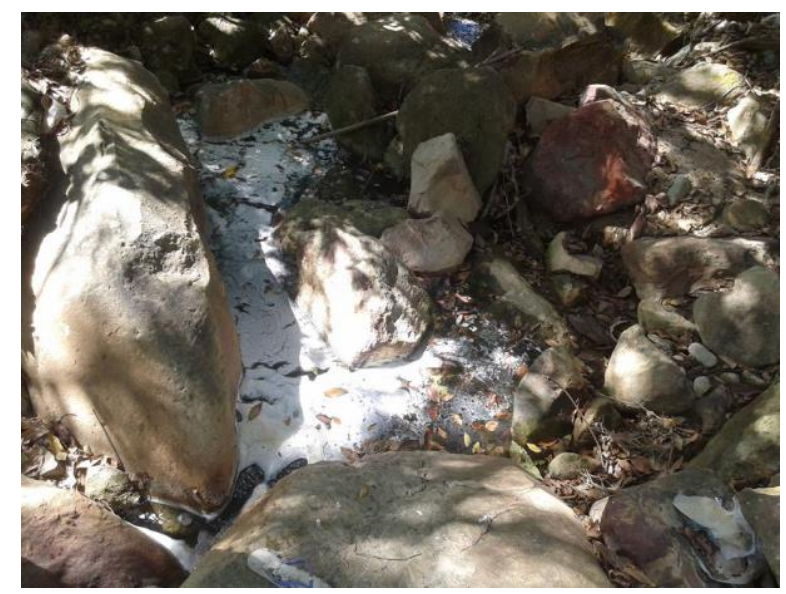

Figura 3. Fotografia mostrando a degradação da qualidade da água próximo ao ponto P2.

Durante a primeira campanha (período chuvoso) o valor do resíduo total do P2 foi de $320 \mathrm{mg} \mathrm{L}^{-1}$, já na segunda campanha (período de estiagem) o valor foi de $1.418 \mathrm{mg} \mathrm{L}^{-1}$ superando inclusive o ponto 3 , que também se mostrou com valor alto $\left(1.392 \mathrm{mg} \mathrm{L}^{-1}\right)$. O resíduo total, segundo a ANA (2015), é toda matéria que permanece na água após um processo de evaporação, secagem ou calcinação da amostra durante um determinado tempo e temperatura, podendo ser, também, denominado de Sólidos Totais.

A justificativa mais apropriada para os valores exorbitantes encontrados consiste no fato de que durante o período de coleta da campanha 2, o TTB se encontrava ativado, ou seja, com sua estrutura de bar/restaurante em pleno funcionamento, o que implica na limpeza da área com maior frequência e também no aumento de visitantes. Já no período da primeira campanha, o TTB estava desativado, sem serviço de bar/restaurante e com a frequência de visitas reduzidas, fato que reflete na diminuição da limpeza da área. Logo, a alteração dos valores pode ser um reflexo do impacto antrópico das atividades de limpeza e lazer. 
Sendo assim, a espuma visualizada na Figura 2 pode ser resultante dos produtos utilizados na limpeza ou até mesmo dos produtos de higiene pessoal, como sabonete e shampoo, usados pelos banhistas durante o banho na Bica.

O uso abusivo destes compostos atua na inibição ou paralisação da depuração natural ou artificial, devido à formação de espumas estáveis (Costa et al., 2007).

Malagutti e Tauk-Tornisielo (2014), ao avaliarem a qualidade das águas do córrego Bandeirantes na sub-bacia do Ribeirão Claro, no município de Rio Claro/São Paulo, concluíram que o ponto de coleta do corpo hídrico em que o valor do resíduo total foi superior a $500 \mathrm{mg} \mathrm{L}^{-1}$ tinha recebido descarga de efluentes.

Blume et al. (2010) concordam que esta variável está relacionada com os ecossistemas terrestres, especialmente o tipo de terra usado, atividades agrícolas e as condições meteorológicas. As amostras coletadas por Blume et al. (2010), em 18/08/08 no Rio dos Sinos, no Sul do Brasil, mostraram um aumento significativo na concentração dos sólidos totais dissolvidos em todos os locais de amostragem, que justificou os resultados como influência da precipitação, que ocorreu no dia anterior à coleta, arrastando materiais sólidos para a bacia.

$\mathrm{Na} \mathrm{MB}$ o aumento acentuado dos resíduos totais foi observado no período de estiagem, não podendo ser atribuindo a chuva este aumento acentuado, e sim, as atividades antrópicas desenvolvidas nos limites da área.

Com relação aos demais parâmetros do $\mathrm{P} 2$, a turbidez e os coliformes termotolerantes na campanha de estiagem foram menos significativos que no período chuvoso, comprovando a influência que a pluviometria exerce sobre estes parâmetros. Já os valores da DBO do P2 foram maiores no período de estiagem, invertendo o resultado do P1, quando a DBO do período de estiagem foi menor que do período chuvoso. Tais valores da DBO do P2 tem relação com os valores do resíduo total, considerando que entre estes estão presentes compostos biodegradáveis, que contribuiriam com o aumento da DBO no período de estiagem, bem como com a maior presença de banhistas e uso do TTB.

\subsubsection{Análise do IQA do Ponto 3 (P3)}

O terceiro ponto (P3) foi a Cachoeira do Pinga, local da área de estudo em que há imersão de banhistas. Sua altitude é de $485 \mathrm{~m}$, este é o ponto de menor altitude, que por se posicionar a jusante de P1 e P2 recebe a carga de seus efluentes. O IQA do P3 se manteve dentro da classe Ruim nos dois períodos analisados.

Dentre os parâmetros que apresentaram valores significativos altos no P3 durante a primeira campanha, destacaram-se a turbidez e os coliformes termotolerantes. A turbidez que se mantinha com valores entre 2,40 uT e $24 \mathrm{uT}$, passou para $36 \mathrm{uT}$ na primeira campanha de coleta. Os coliformes termotolerantes que estavam na faixa entre $36 \mathrm{NMP} / 100 \mathrm{ml}$ e 94 NMP/100 ml nas outras análises, subiu para 167 NMP/100 ml.

Essas variações são esperadas, já que, de acordo com Bonet et al. (2008), os picos de turbidez, cor e coliformes termotolerantes estão essencialmente associados à cheia. Durante o período chuvoso, há um maior aporte de sedimentos para o leito dos rios, estes além de aumentarem a turbidez trazem consigo mais coliformes para o corpo hídrico. Para fins do cálculo do IQA, o parâmetro coliformes termotolerantes possui peso significativo em relação à maioria dos parâmetros, o peso para este parâmetro é 0,15 ficando atrás apenas do OD que é de 0,17 .

Porém, o OD no P3 também foi maior do que nos demais pontos, tendo em vista o peso significativo que possui no cálculo do IQA, o OD pode ter influenciado a classe de qualidade da água. A análise da concentração de oxigênio dissolvido permite avaliar a condição aeróbica dos cursos de água, devido à entrada de poluentes. A solubilidade do mesmo se dá em função da temperatura, da altitude local e da salinidade da água (Jordão et al., 2007). 
É interessante observar a seguinte relação: o P3 apresentou concentrações de DBO e de OD maiores que o P1 e o P2, contrariando a relação inversamente proporcional que vinha acontecendo nos demais pontos analisados, de que quanto maior a DBO menor o OD do corpo hídrico. Uma das explicações para isto está fundamentada na renovação do oxigênio que ocorre mais rapidamente na Cachoeira do Pinga, tendo em vista que a agitação do corpo aquático que possui cachoeiras ou quedas d'água contribui com o aumento do fluxo de renovação do oxigênio a partir do ar atmosférico.

$\mathrm{O}$ resíduo total do último ponto também seguiu a tendência do $\mathrm{P} 2$, e durante o período de estiagem apresentou a concentração de $1.392 \mathrm{mg} \mathrm{L}^{-1}$, sendo observado também na Cachoeira do Pinga espumas em alguns pontos. Um dos impactos que podem ser desencadeados pela alta concentração de resíduos totais é sentido na vida aquática, à medida que os materiais vão se depositando no leito do rio eles destroem os organismos que vivem nos sedimentos e servem de alimento para outros organismos, além disso, danificam os locais de desova de peixes (Bufon et al., 2014).

Verissímo e Ferreira (2013) concluíram em seu trabalho no baixo curso do rio São João que as concentrações dos resíduos totais podem ter influenciado nos valores obtidos pelo IQA, tendo em vista que apresentaram valores muito elevados em alguns pontos. Tal constatação se adequa à realidade dos pontos $\mathrm{P} 2 \mathrm{e} \mathrm{P} 3$, que tiveram seus valores de resíduos aumentados durante o período da campanha 2, na qual o TTB se encontrava ativado.

O P1 não refletiu a influência da ativação do TTB porque se encontra à montante da bica, local onde os banhistas tomam banho e utilizam produtos de higiene pessoal, e do próprio local da área (espelho d'água, pátio do TTB, restaurante, banheiros).

Ao comparar os 3 pontos de análise, observou-se que parâmetros como $\mathrm{pH}$ e temperatura se mantiveram controlados, não apresentando picos de elevação. $\mathrm{O}$ pH variou de 5,0 a 6,3 nas análises e a temperatura ficou entre $21^{\circ}$ e $27^{\circ}$. A temperatura da água contribui com o retardamento ou aceleração da atividade biológica, na absorção de oxigênio e precipitação de compostos. Conforme Buzelli e Cunha-Santino (2013), o aumento da temperatura "tem como consequência a intensificação da taxa de decomposição da matéria orgânica, aumentando a demanda bioquímica de oxigênio do ambiente aquático". Esta relação compromete a conservação da fauna aquática.

Dada às constatações e discussões feitas, pode-se concluir que os IQAs obtidos foram condizentes com as evidências observadas em campo e que qualidade da água diminui à medida que o Riacho da Bica desce a vertente (Tabela 3). O P1 obteve a classe Razoável (faixa 51-70), o trecho intermediário (P2) e a Cachoeira do Pinga (P3) manteve a classe Ruim (faixa 26 - 50). Contudo, nota-se uma leve melhora na condição do $\mathrm{P} 3$ durante o período seco em comparação com o P2. Tal condição pode ser reflexo dos parâmetros como turbidez e resíduo total que no P2 foram maiores que no P3 durante a segunda campanha, bem como o OD que foi menor do que no P3. Em sentido contrário, as diferenças nos parâmetros não foram suficientes para melhorar a o IQA como um todo, se mantendo como Ruim nos dois últimos pontos de análise.

Tabela 3. Resultados do Índice de Qualidade (IQA) da Água no Riacho da Bica, Portalegre, RN, Brasil.

\begin{tabular}{lccl}
\hline & \multicolumn{2}{c}{ IQA } & \\
\cline { 2 - 3 } Ponto analisado & período chuvoso & Período de estiagem & Categoria \\
\hline Ponto 1 - Altitude 620 m & 55,8 & 58,2 & IQA Razoável \\
Ponto 2 - Altitude 570 m & 43,7 & 42,8 & IQA Ruim \\
Ponto 3 - Altitude 485 m & 42,4 & 44,5 & IQA Ruim \\
\hline
\end{tabular}




\subsection{Análise da balneabilidade da Cachoeira da Bica}

Os valores de E. coli utilizados para caracterizar a balneabilidade da Cachoeira do Pinga merecem atenção especial, já que a sua presença denuncia a ocorrência de contaminação de origem fecal, podendo ser relacionada diretamente com bactérias patogênicas que apresentam risco a saúde humana.

Durante as cinco semanas de monitoramento os valores de E. coli, foram contabilizados no total em 248 UFC. Isoladamente, nenhuma amostra apresentou concentração superior a 80 UFC/100 ml. Neste aporte, concluiu-se que a Cachoeira do Pinga se enquadra na categoria "Excelente" para balneabilidade, uma vez que pelo menos $80 \%$ das amostras ou mais de um conjunto de amostras obtidas apresentaram concentrações de E. coli de no máximo $200 \mathrm{UFC} / 100 \mathrm{ml}$ (Brasil, 2000).

Estes resultados são coerentes com o local analisado, considerando que a contaminação por E. coli é maior em águas que estão submetidas aos impactos da pecuária e das cidades que apresentam elevado grau de urbanização e adensamentos populacionais. Essas características não se enquadram significativamente a Portalegre, que possui uma população de 7.760 habitantes (IBGE, 2014), um grau de urbanização embrionário, e atividades agrossilvopastoris de pequena escala. Tais fatos não justificariam altos valores de E. coli.

Entretanto, deve-se alertar para o fato da cidade não possuir mecanismos de coleta e disposição de esgotamento sanitário adequado, prevalecendo fossas rudimentares, que propiciam a contaminação do solo e das águas. Atualmente, a situação não é crítica, mas em um cenário futuro, de aumento da população e urbanização, esta situação pode ser agravada, revelando altos valores de microorganismos patogênicos. O período de precipitação também pode promover um maior aporte desses organismos no corpo hídrico, já a análise microbiológica deste trabalho se delimitou ao período de estiagem.

Todavia, cabe ressaltar que a classe "Excelente" é uma classe ideal para banho, porém, se os valores de E. coli aumentarem na Cachoeira do Pinga, é possível que se atinja a classes menos favoráveis. Tais cenários indesejáveis podem vir a ser vivenciados, por exemplo, na época de chuva, onde há o aumento significativo de bactérias como a $E$. coli nas águas superficiais.

As chuvas interferem nas concentrações de bactérias na água da seguinte forma: inicialmente, com as chuvas há maior carreamento de material fecal por meio do escoamento superficial em áreas rurais e urbanas, além de galerias pluviais e córregos para o local de análise, o que aumenta os valores medidos. Posteriormente, as chuvas arrastam as bactérias do local de análise e os valores diminuem. Assim o carreamento de material fecal no início das chuvas compromete a qualidade das águas nos balneários e altera os valores monitorados (WHO, 2003).

Como o período de coleta e monitoramento desenvolvido na Cachoeira do Pinga correspondeu ao período de estiagem na região, as análises não refletiram de maneira geral as influências da chuva, apesar de que na semana 3 (19/11/2014) foi perceptível na paisagem que tinha chovido em dias anteriores, sendo presenciada ainda na manhã da coleta uma neblina na região. Tal evento pode ter contribuído com variação exacerbada das concentrações de $E$. coli, entre a primeira e terceira semana de coleta, as quais variaram de 80 para 2 e novamente $60 \mathrm{UFC} / 100 \mathrm{ml}$.

Diante dos resultados obtidos nas análises da Cachoeira do Pinga, não se faz necessário à adoção de medidas corretivas, porém, não se deve desprezar o investimento em ações preventivas. O ideal é estabelecer um modelo de monitoramento da balneabilidade para que a Cachoeira seja avaliada com certa frequência, tanto em período chuvoso, como de estiagem.

Segundo o modelo de monitoramento apresentado por Lopes (2012), a partir de diretrizes desenvolvidas para a Nova Zelândia, se em um conjunto de amostras analisadas, todos os resultados das amostras apresentarem um somatório < 260 NMP/100 ml deve-se manter uma 
rotina de monitoramento semanal; se posteriormente, uma única amostra apresentar >260 NMP/100 ml, deve ser feito uma amostragem diária e identificação da fonte de contaminação; e em casos de resultados consecutivos realizados com o intervalo mínimo de 24 horas, apresentarem valores $>550$ a amostragem deve ser diária, a fonte da contaminação deve ser investigada e além disso o público deve ser notificado sobre a situação.

Morais e Silva (2012), ao avaliarem o balneário Curva São Paulo, no rio Poti, em Teresina-Piauí, estabeleceram para o ponto de balneabilidade "Satisfatória", um monitoramento que deve ser iniciado cinco semanas antes do período de estiagem. A escolha do período pelos autores pode ter se dado em virtude de ser o período de estiagem aquele em que há maior procura por balneários, nesta perspectiva um dos objetivos do programa de monitoramento é informar o banhista quanto a qualidade da água.

Além disso, o trabalho de limpeza das margens deve ser feito periodicamente e as condições de acesso ao rio melhorado. A instituição responsável pelo programa de monitoramento seja o órgão competente do estado ou do município, não pode esquecer, sobretudo, da adequada sinalização do local com placas indicando a condição de uso do balneário (Morais e Silva, 2012).

Dada à discussão acerca dos resultados obtidos na Cachoeira do Pinga cabe aqui correlaciona-los com outras experiências desenvolvidas dentro do mesmo contexto. Um trabalho similar desenvolvido por Andretta et al. (2008) no município de Carrancas, localizado no Sul de Minas Gerais analisou a balneabilidade a partir da contagem de coliformes fecais de duas Cachoeiras da região, a Cachoeira da Fumaça e a Cachoeira do Véu da Noiva. De acordo com os resultados obtidos a balneabilidade da primeira Cachoeira foi classificada como imprópria, em virtude dos valores de coliformes fecais se mostrarem superior a $1000 \mathrm{UFC} / 100 \mathrm{ml}$ e a segunda Cachoeira foi considerada excelente, uma vez que os valores não excederam 250 UFC/100 ml (Andretta et al., 2008).

Os resultados obtidos por Andretta et al. (2008) são reflexos diretos da relação de uso e ocupação do solo. A montante da Cachoeira do Véu da Noiva há o predomínio de áreas de pastagens com presença de mata ciliar em diversos pontos. Em contrapartida a montante da Cachoeira da Fumaça se situa a própria área urbana do município e fazendas com áreas destinadas aos campings. Sendo assim, o estudo constatou que a contaminação aferida pelas análises denota o excesso de carga poluidora advinda dos esgotos da cidade de Carrancas, sem tratamento prévio, e que são lançados no curso d'água que dá origem à Cachoeira da Fumaça.

Para a problemática das Cachoeiras supracitadas Andretta et al. (2008) destacam como soluções o investimento no tratamento de esgoto, a avaliação periódica das condições de balneabilidade nas áreas de banho e divulgação das informações, a dessedentação do gado feita fora dos limites das matas ciliares e a recuperação da vegetação ciliar bem como de outras Áreas de Preservação Permanentes.

Todas estas considerações podem ser aplicadas a área da Cachoeira do Pinga, pois mesmo não sendo caracterizada uma cidade de núcleo populacional adensado, Portalegre apresenta deficiências quanto ao saneamento ambiental, constatando-se ainda áreas de Preservação Permanente como os olhos d'agua com suas margens desmatadas ou com atividades impactantes bem próximas.

Situação que reforça a aplicação de um plano de monitoramento da balneabilidade e que este possa ocorrer preferivelmente em períodos de estiagem e em estações chuvosas, já que com a interferência pluviométrica a densidade de bactérias é alterada.

Visando um maior conhecimento sobre a caracterização da balneabilidade da Cachoeira do Pinga é importante destacar a Resolução CONAMA 357 de 17 de março de 2005 (Brasil, 2005), que apresenta as diretrizes ambientais para a classificação dos corpos de água, conforme a qualidade requerida para os seus usos preponderantes. Segundo a resolução, os 
corpos d'água enquadrados nas classes I e II podem ser destinados à recreação de contato primário, dependendo das condições e padrões de qualidade da água, entre eles, são importantes parâmetros como Turbidez, pH, DBO e OD.

No dia 26 de novembro de 2014, quarta semana do monitoramento da balneabilidade, foi feita além da análise de E. coli a análise de outros parâmetros como $\mathrm{pH}$, turbidez, DBO e OD. Para o pH o valor obtido foi de 6.3, e para turbidez foi de 6,65 UNT (Unidades Nefelométrica de Turbidez), ambas medidas se encontram enquadradas como características de águas doces de classe 2, onde o pH deve permanecer dentro da faixa de 6 e 9 e a turbidez deve ser de até 100 UNT. Esses resultados confirmam a boa qualidade de balneabilidade da água, principalmente, a turbidez que quando alta passa a impressão de água suja e afastam as pessoas do local.

O pH ótimo para o crescimento e desenvolvimento da E. coli é de 6,0 a 8,0, coincidindo com os valores de $\mathrm{pH}$ encontrados na água, isso explica o motivo da água ser considerada fonte potencial de contaminação de coliformes (Cerqueira et al., 2006). Em contrapartida, a taxa de mortalidade da E. coli dependerá da temperatura da água, dos efeitos da luz solar, das populações de outras bactérias presentes e das alterações na composição química da água (Juarez e Rajal, 2013).

O OD da Cachoeira do Pinga também está em conformidade com os parâmetros dos corpos d'água de classe I e II, sendo verificado o valor de $10,55 \mathrm{mg} \mathrm{L}^{-1}$. De acordo com a resolução 357 do CONAMA (Brasil, 2005) o OD para classe I não pode ser inferior a $6 \mathrm{mg} \mathrm{L}^{-1}$ e para classe II não deve ser inferior a $5 \mathrm{mg} \mathrm{L}^{-1}$. Apesar de o valores supracitados estarem de acordo com os padrões legais, a DBO não se enquadrou, constatando-se o valor de 24,49 $\mathrm{mg} \mathrm{L}^{-1}$, muito superior ao estabelecido pelo CONAMA. Este valor significativo da DBO pode estar relacionado à interferência antrópica local, a qual se caracteriza pelo uso e ocupação indevido do solo e pela disposição de efluentes domésticos in natura no manancial, uma vez que o município não possui infraestrutura adequada para o saneamento ambiental.

Esta situação pode ser identificada em muitos municípios brasileiros. Segundo Damasceno et al. (2015) o Rio Amazonas situado na cidade de Macapá, estado do Amapá, reflete a poluição hídrica ocasionada pelo crescimento espacial desordenado e a consequente escassez de serviços de saneamento básico.

Por fim, mediante os resultados e contribuições afere-se a Cachoeira do Pinga além da classificação da água como "Excelente" segundo o CONAMA (Brasil, 2000). Além disso, havendo a diminuição e o controle da DBO a Cachoeira poderá ser enquadrada também como "águas doces de classe 2" com base na resolução 357 do CONAMA (Brasil, 2005) a qual estabelece como usos permissivos para essa classe à recreação de contato primário, tais como natação, esqui aquático e mergulho.

É interessante destacar que apesar de possuir excelente qualidade para banho, as águas da Cachoeira do Pinga apresentaram um IQA ruim, conforme discutido anteriormente (tópico 3.1.3. Análise do IQA do Ponto 3). Na Cachoeira os valores para DBO e resíduo total no período de estiagem se mostraram muito acima dos padrões adequados, isto pode ter afetado em maior grau a qualidade da água, ponderando que estes parâmetros, em especial, promovem poluição visual e a escassez qualitativa da água. A DBO esta relacionada à presença de macronutrientes, que quando alta diminui OD, logo há o prejuízo da condição aeróbica do corpo hídrico para os organismos aquáticos, nesta mesma direção, os resíduos totais causa danos à vida aquática, uma vez que grande parte da fauna presente nos sedimentos é destruída pela carga poluidora que chega as águas.

\section{CONCLUSÃO}

As evidências coletadas e discutidas neste trabalho demonstram que a poluição visual da 
área é uma realidade que decorre da ausência de programas de educação ambiental com os visitantes e moradores que frequentam a microbacia da Mata da Bica. Sendo, portanto, verificado a presença de resíduos sólidos no TTB (P1), no trecho intermediário do Riacho da Bica (P2) e na Cachoeira do Pinga (P3), locais em que há circulação de visitantes. Esta poluição observada na $\mathrm{MB}$ se caracteriza como pontual e pode ser revertida com medidas corretivas e de prevenção.

No que diz respeito ao IQA, os resultados obtidos apontam que a qualidade das águas é prejudicada à medida que desce a vertente, no P1 a água permanece com a classe razoável durante o período de chuva e estiagem, já no P2 e P3 a água se mantém na classe ruim nos dois períodos. Isto mostra que a declividade favorece o transporte e o acúmulo de contaminantes para altitudes mais baixas. A resolução para tal cenário consiste no manejo adequado da área principalmente no seu ponto mais alto, a partir do controle efetivo das fontes pontuais e difusas de contaminação.

Quanto à balneabilidade, a Cachoeira do Pinga se enquadrou como excelente no período de estiagem analisado, todavia o resultado obtido não diminui a importância de um programa de monitoramento, e que este seja feito no período chuvoso e também durante a estiagem, principalmente próximo à época de maior incidência de visitantes na área.

\section{AGRADECIMENTOS}

Os autores agradecem a Fundação de Coordenação de Aperfeiçoamento de Pessoal de Nível Superior - CAPES pela bolsa de mestrado vinculada ao Programa de Demanda Social da Universidade do Estado do Rio Grande do Norte, concedida à primeira autora deste artigo, derivado de parte da Dissertação de Mestrado da primeira autora apresentada ao Programa de Pós Graduação em Ciências Naturais, da Universidade do Estado do Rio Grande do Norte.

\section{REFERÊNCIAS}

ASSOCIAÇÃO BRASILEIRA DE NORMAS TÉCNICAS - ABNT. NBR 9898: Preservação e técnicas de amostragem de efluentes líquidos e corpos receptores. Rio de Janeiro, 1987.

AGENCIA NACIONAL DE ÁGUAS - ANA (Brasil). Índice de qualidade das águas. 2015. Disponível em: http://portalpnqa.ana.gov.br/indicadores-indice-aguas.aspx\#. Acesso em: 10 jun. 2015.

ANDRETTA, V.; PEREIRA, J. A. A.; MACEDO, R. L. G.; LOPES, F. W. A.; VITORINO, M. R. Impactos ambientais e perfil dos visitantes no complexo da Cachoeira da Fumaça em Carrancas/MG. Caderno Virtual de Turismo. v. 8, n. 1, p.57-68, 2008. http://repositorio.ufla.br/jspui/handle/1/717

ANDRIETTI, G.; FREIRE, R.; AMARAL, A. G.; ALMEIDA, F. T.; BONGIOVANI, M. C.; SCHNEIDER, R. M. Índices de qualidade da água e de estado trófico do rio Caiabi, MT. Revista Ambiente \& Água, v. 11, n. 1, 2016. http://dx.doi.org/10.4136/ambiagua. 1769

AMERICAN PUBLIC HEALTH ASSOCIATION - APHA; AMERICAN WATER WORKS ASSOCIATION - AWWA; WATER ENVIRONMENTAL FEDERATION - WEF. Standard methods for the examination of water and wastewater. 21th ed. Washington, 2005. 
BRASIL. Resolução no 274 de 29 de novembro 2000. Dispõe sobre a balneabilidade dos corpos hídricos e a classificação das águas, doces, salobras e salinas. Diário Oficial [da] União, Brasília, 18 jun. 2000.

BRASIL. Resolução n ${ }^{\circ}$ 357, de 17 de março de 2005. Dispõe sobre a classificação dos corpos de água e diretrizes ambientais para o seu enquadramento, bem como estabelece as condições e padrões de lançamento de efluentes, e dá outras providências. Diário Oficial [da] União, Brasília, 18 mar. 2005.

BRASIL. Manual prático de análise de água. 2. ed. rev. Brasília: Fundação Nacional de Saúde, 2006.

BLUME, K. K.; MACEDO, J. C.; MENEGUZZI, A.; SILVA, L. B.; QUEVEDO, D. M.; RODRIGUES, M. A. S. Water quality assessment of the Sinos River, Southern Brazil. $\begin{array}{llllllll}\text { Brazilian Journal of Biology, } & \text { v. } 70, \quad \text { n. } 4, \quad \text { p. } & 1185-1193, & \end{array}$ http://dx.doi.org/10.1590/S1519-69842010000600008

BONNET, B. R. P.; FERREIRA, L. G.; LOBO, F. C. Relações entre qualidade da água e uso do solo em Goiás: uma análise à escala da bacia hidrográfica. Revista Árvore, v. 32, n. 2, p. 311-322, 2008. http://dx.doi.org/10.1590/S0100-67622008000200014

BUFON, A. G. M.; BOCK, C. L.; TAUK-TORNISIELO, S. M.; MELO, J. S. C.; CANTELMO, O. A.; FERNANDES, A. O. et al. Sedimentation Rates in Cachoeira de Cima Reservoir, Mogi Guaçu municipality, SP, Brazil. Holos Environment, v. 14, n. 2, p. 114-123, 2014.

BUZELLI, G. M.; CUNHA-SANTINO, M. B. Análise e diagnóstico da qualidade da água e estado trófico do reservatório de Barra Bonita, SP. Revista Ambiente \& Água, v. 8, n. 1, 2013. http://dx.doi.org/10.4136/ambi-agua.930

CERQUEIRA, M. M. O. P.; PICINIM, L. C. A.; FONSECA, L. M.; SOUZA, M. R.; LEITE, M. O.; PENNA, C. F. A. M. et al. Qualidade da água e seu impacto na qualidade microbiológica do leite. In: MESQUITA, A. J.; COELHO, K. O. Perspectivas e avanços na qualidade do leite no Brasil. Goiânia: Talento, 2006. p. 273-290.

COMPANHIA AMBIENTAL DO ESTADO DE SÃO PAULO - CETESB. Cálculo online do IQA. 2015. Disponível em: http://sobreasaguas.info/iqa_cetesb.aspx. Acesso em: 05 dez. 2015.

COSTA, M. J. C.; SOUSA, J. T.; LEITE, V. D.; LOPES, W. S.; SANTOS, K. D. Co-digestão anaeróbia de substâncias surfactantes, óleo e lodo de esgoto. Engenharia Sanitária e Ambiental, v. 12, n. 4., p. 433-439, 2007. http://dx.doi.org/10.1590/S141341522007000400010

DAMASCENO, M. C. S.; RIBEIRO, H. M. C.; TAKIYAMA, L. R.; PAULA, M. T. Avaliação sazonal da qualidade das águas superficiais do Rio Amazonas na orla da cidade de Macapá, Amapá, Brasil. Revista Ambiente \& Água, v. 10, n. 3, 2015. http://dx.doi.org/10.4136/ambi-agua.1606

FRANCENER, S. F.; ANDRADE, L. R.; MOREIRA, J. P. P. C.; NUNES, M. L. A.; GOMES, J. B.; SANTOS, L. R. et al. Avaliação do índice de balneabilidade em uma área de lazer no município de Ji-Paraná - Rondônia. In: SIMPÓSIO BRASILEIRO DE RECURSOS HÍDRICOS, 19., 2011, Alagoas. Anais... São Paulo: ABRH, 2011. p. 1-9. 
FERREIRA, K. C. D.; LOPES, F. B.; ANDRADE, E. M.; MEIRELES, A. C. M.; SILVA, G. S. S. Adaptação do índice de qualidade da água da National Sanitation Foundation ao semiárido brasileiro. Revista Ciência Agronômica, v. 46, n. 2, 2015.

FREITAS, E. V. C.; BARRETO, F. M. S.; NUNES, A. B. A.; ALENCAR, M. F. Índice de qualidade da água bruta do Açude Gavião - Município de Pacatuba. In: CONGRESSO BRASILEIRO DE ENGENHARIA SANITÁRIA E AMBIENTAL, 26., 2011, Porto Alegre. Anais... São Paulo: ABES, 2011.

HACHICH, E. M.; BARI, M. D.; CHRIST, A. P. G.; LAMPARELLI, C. C.; RAMOS, S. S.; SATO, M. I. Z. Comparison of thermotolerant coliforms and escherichia coli densities in freshwater bodies. Brazilian Journal of Microbiology, p. 675-681, 2012. http://dx.doi.org/10.1590/S1517-83822012000200032

INSTITUTO BRASILEIRO DE GEOGRAFIA E ESTATÍSTICA - IBGE. Informações completas de Portalegre-RN. 2014. Disponível em: http://www.cidades.ibge.gov. br/xtras/perfil.php?lang=\&codmun=241020. Acesso em: 08 jan. 2015.

INSTITUTO DE DESENVOLVIMENTO SUSTENTÁVEL E MEIO AMBIENTE DO RN IDEMA. Perfil do seu município: Portalegre. 2008. Disponível em: http://adcon.rn.gov.br/ACERVO/idema/DOC/DOC000000000013907.PDF. Acesso em: 10 jul. 2015.

JORDÃO, C. P.; RIBEIRO, P. R. S.; MATOS, A. T.; FERNANDES, R. B. A. Aquatic contamination of the turvo limpo river basin at the Minas Gerais state, Brazil. Journal of Brazilian Chemistry Society, v. 18, n. 1, p. 116-125, 2007. http://dx.doi.org/10.1590/S0103-50532007000100013

JUAREZ, M. M.; RAJAL, V. B. Parasitosis intestinales en Argentina: principales agentes causales encontrados en la población y en el ambiente. Revista Argentina de Microbiologia v. 45, n. 3, p. 191-204, 2013. http://dx.doi.org/10.1016/S03257541(13)70024-5

LOPES, F. W. A. Proposta metodológica para avaliação de condições de balneabilidade em águas doces no Brasil. 2012. 199 f. Tese (Doutorado em Geografia) - Universidade Federal de Minas Gerais, Belo Horizonte, 2012.

LOPES, F. W. A.; MAGALHÃES JUNIOR, A. P. Avaliação da qualidade das águas para recreação de contato primário na bacia do alto Rio das Velhas - MG. HYGEIA Revista Brasileira de Geografia Médica e da Saúde v. 6, n. 11, p. 133-149, 2010.

MALAGUTTI, E. N; TAUK-TORNISIELO, S. M. Qualidade das águas do córrego bandeirantes na sub-bacia do ribeirão claro, município de Rio Claro, SP, Brasil. Holos Environment, v. 14, n. 2, p. 135-152, 2014.

MANOEL, L. O.; CARVALHO, S. O. Avaliação do índice de qualidade de água (iqa) de duas nascentes no município de Ilha Solteira-SP. 2014. Disponível em: http://www.feis.unesp.br/Home/Eventos/encivi/viiencivi-2013/21---avaliacao-doindice-de-qualidade-de-agua-iqa-de-duas-nascentes-no-municipio-de-ilha-solteirasp.pdf. Acesso em: 28 nov. 2015.

MARQUEZI, M. C.; GALLO, C. R.; DIAS, C. T. S. Comparação entre métodos para a análise de coliformes totais e E. coli em amostras de água. Revista do Instituto Adolfo Lutz, v. 69, n. 3, p. 291-296, 2010. 
MEDEIROS, S. R. M. Análise da viabilidade socioambiental para a criação de uma unidade de conservação na microbacia da Mata da Bica, Portalegre (RN). 2015. 148f. Dissertação (Mestrado em Ciências Naturais) - Universidade do Estado do Rio Grande do Norte, Mossoró, 2015.

MIYAZAWA, M.; PAVAN, M. A.; MURAOKA, T.; CARMO, C. A. F. S.; MELLO, W. J. Análise química de tecido vegetal. In: SILVA, F. C (Org.). Manual de análises químicas de solos, plantas e fertilizantes. Brasília: Embrapa, 1999.

MORAIS, R. C. S.; SILVA, C. E. Diagnóstico ambiental do balneário Curva São Paulo no rio Poti em Teresina, Piauí. Engenharia Sanitária e Ambiental, v. 17, n. 1, p.41-50, 2012. http://dx.doi.org/10.1590/S1413-41522012000100008

MORAIS, E. B. Indicadores microbiológicos, metais e Índice de Qualidade da Água (IQA) associados ao uso e ocupação da terra para avaliação da qualidade ambiental da microbacia do rio Cabeça, na bacia do rio Corumbataí, SP. 2010. 138p. Tese (Doutorado em ciências biológicas) - Universidade Estadual Paulista, São Paulo, 2010.

SANTI, G. M.; FURTADO, C. M.; MENEZES, R. S.; KEPPELER, E. C. Variabilidade espacial de parâmetros e indicadores de qualidade da água na sub-bacia hidrográfica do Igarapé São Francisco, Rio Branco, Acre, Brasil. Ecología Aplicada, v. 11, n. 1, p. 23 31, 2012.

SATO, M. I. Z.; HACHICH, E. M.; MENEGON JUNIOR, N.; MELO, A. M. J.; COELHO, M. C. L. S.; BARI, M. D. et al. Monitoramento de Escherichia coli e coliformes termotolerantes em pontos da rede de avaliação da qualidade de águas interiores do Estado de São Paulo. São Paulo: CETESB, 2008. 21p.

SILVA, A. G.; SOUZA, L. D. Efeitos antrópicos e sazonais na qualidade da água do rio do Carmo. Holos, v. 5, ano 29, 2013.

SILVA, A. G. Estudo da influência antrópica na qualidade da água do rio do Carmo. 2013. 98f. Dissertação (Mestrado em Ciências Naturais) - Universidade do Estado do Rio Grande do Norte, Mossoró, 2013.

SILVA, V. P. R.; PEREIRA, E. R. R.; ALMEIDA, R. S. R. Estudo da variabilidade anual e intra-anual da precipitação na região nordeste do Brasil. Revista Brasileira de Meteorologia, v. 27, n. 2, p. 163-172, 2012. http://dx.doi.org/10.1590/S010277862012000200005

VERÍSSIMO, F. A. R.; FERREIRA, M. I. P. Aplicação do Índice de Qualidade da Água (IQA) para caracterização do baixo curso do Rio São João. Boletim do observatório ambiental Alberto Ribeiro Lamego, v. 7, n. 2, p. 181-197, 2013. http://dx.doi.org/10.5935/2177-4560.20130021

WORLD HEALTH ORGANIZATION - WHO. Guidelines for safe recreational water environments - coastal and fresh waters. Geneva, 2003. 253p. 